\title{
陈鹤琴幼儿教育研究方法的特点及启示
}

\author{
邓雯雯
}

毕节幼儿师范高等专科学校

DOI:10.32629/er.v3i3.2541

[摘 要] 陈鹤琴是我们中国幼儿教育的奠基人、开拓者,被称为中国幼教之父。在幼儿教育的研究上,他采用了临床研究方法,开展了以 “试验” 为基础的科学的幼儿教育研究。本文通过分析陈鹤琴幼儿教育研究方法的特点, 去探索这种植根于本土的研究方法对当今中国学前教育研究有 何启示。

[关键词] 陈鹤琴; 幼儿教育; 研究方法

陈鹤琴是中国著名的儿童教育专家和心理学家, 他是中国现代学前教 育的重要奠基人, 现代实验性幼儿园课程的开创者和引领者, 是中国幼儿 教育科学化的先驱。在他的引领下, 中国的幼儿教育, 不断吸纳先进理念, 扎根中国文化和幼儿教育的实践, 不断向着科学化的道路迈进。

笔者通过知网进行文献检索, 发现国内主要是从儿童心理、家庭教育、 “活教育” 理论和陈鹤琴幼儿教育思想运用幼儿园实践等展开的研究, 而 关于陈鹤琴幼儿教育研究方法这一视角的文章很少。因此通过研读陈鹤琴 幼儿教育思想的论著, 及相关的文献资料, 对陈鹤琴幼儿教育研究方法的 特点进行梳理, 以期对当今中国学前教育研究方法有所启示, 促进中国幼 儿教育科学化。

\section{1 陈鹤琴幼儿教育研究方法的特点}

1.1中国化

陈鹤琴是科学的儿童教育的积极推动者, 作为留美学者, 他反对纯粹 的“美国式”教育, 认为应该借鉴西方优秀的思想和内容, 但不能一味模仿。 主张 “洋为中用”, 体现中国化。例如: 镜画试验, 结果得出, 在教儿童读 书做事时, 要随时让他们知道读书做事的结果, 不然他们的兴趣会降低, 进 步也会逐步减少。陈鹤琴针对儿童教育的研究是将国外的理论与方法进行 亲身实践, 经过消化吸收, 使之成为符合我国研究儿童的理论和方法。

\section{2 科学化}

陈鹤琴对儿童心理的研究采用了当时比较先进的临床研究方法, 采用 个案观察和日志记录孩子的发展。其中, 他对长子陈一鸣的儿童心理研究, 既介绍了国外的研究理论, 同时以时间为节点, 使用观察日记的方法记录 其儿子的发展变化。通过 808 天的观察记录, 在验证国外研究的同时, 又提 出自己的观点, 并且依据其研究结果对儿童的教育提出科学合理的建议, 给教育工作者提供更多的参考。这使他的《儿童心理之研究》不是照搬或 模仿西方的儿童心理学理论, 而是扎扎实实的实证研究的成果。而在当今 学前儿童教育和研究处于分裂的情况下, 这种扎实的科学的研究方法值得 我们学习与借鉴。

1. 3 重实证、实验研究

在幼儿教育的研究上, 陈鹤琴开展了以 “试验” 为基础的科学的幼儿 教育研究, 采用行动研究的方法论, 利用教育现场展开研究。为此, 他专门 建立了我国历史上第一所实验幼儿园一一南京鼓楼幼稚园 (1923), 也是我 国第一个高等院校 (当年的国立东南大学教育科)幼儿教育实验研究基地, 开创了我国高等院校理论联系实际, 开设定点实验研究基地的先河。他担 任园长, 张宗麟为助手, 对幼儿园环境、幼稚园课程、教材教法、玩具、设 备、音乐、幼儿园故事、儿童习惯、幼儿园日常管理等进行了全方位的实 验研究。在探索幼儿教育研究的过程中, 始终不渝的坚持理论研究与亲身 实践相结合, 只有通过自己的验证后才会去实践, 将其转化为自己的理论
观点。

1. 4 注重量的分析

纵观陈鹤琴的所有研究, 他非常注重量化的研究方法和量的分析。 1921年, 他和廖世承合著出版《智力测验法》, 成为中国最早的教育测验专 著, 开创了 “中国的教育测验运动”; 1925年, 他们又合作编写了《测验概 要》一书, 该书有详尽的、可操作性非常强的实施测验的方法和统计方法 介绍, 使用便利, 直接推动了教育测验和心理测验的开展。此外, 他通过实 施、宣传、编制量表和介绍方法, 把智力和教育测量推广到中小学, 把测量 运动推向高潮。

1.5 兼容并蓄, 博各家之长

陈鹤琴在研究不同问题的过程中, 不是单一采用某一种研究方法, 而 是兼容并蓄, 博各家之长, 补一家之短。如在儿童理解能力和儿童言语与思 想的研究中, 充分结合实证研究和行动研究的方法, 既做数据的统计分析 又做质性的深入分析。在儿童美感与绘画的研究中, 采用观察法和实验法, 进行长达几年的研究, 发现儿童绘画特点与学习方式, 并在1956年的南师 大科学研究大会上, 做了《从一个儿童的图画发展过程中看他的心理之发 展》的学术研究报告。

\section{2 陈鹤琴幼儿教育研究方法的启示}

2. 1 具有科学研究的精神

研究精神是一位研究者投身研究工作的动力。纵观陈鹤琴对幼儿教育 理论的探索以及长期的实践, 我们可以看出, 他留给我们的精神财富是非 常丰富的。第一, 献身教育的精神; 第二, 中西融通的创造精神; 第三, 理 论与实际相结合的改革精神。在当今的教育界, 存在教师买卖论文, 为了评 职称做资料等文风不正的现象, 教师的职称、薪金等与论文挂钩。当幼儿 教师成为养家活口的职业, 幼教工作者也就不具备所谓科学研究精神。

目前培养幼儿教师的师范类学校以高职、专科学校为主, 可是这些学 校缺乏自己的附属幼儿园, 高校教师虽然具备研究能力但是却脱离实际, 与当地幼儿园的联系仅仅只为了完成学生实习工作, 没有搭建科研合作的 平台, 彼此对于是否具备研究和指导能力存怀疑态度, 因此, 存在理论与实 际相脱节的现象。正是这样, 我们更要像 “幼教之父” 陈鹤琴先生学习他 的科学研究精神, 特别是理论与实际相结合的改革精神, 给了我们一个很 深的启迪: 教育理论不是高高在上的, 不是写在书本里的理论, 是要与实践 相结合, 通过改革来推行知行合一。

2. 2 注意研究的中国化和科学化

陈鹤琴对美国的进步教育非常熟悉, 但是他结合中国国情进行在创造, 无论是他的《儿童心理之研究》, 或者《家庭教育》都是中西融通的, 而且 他都是中国的语境。还有玩具, 国外有的幼稚园的玩具很贵, 我们买不起, 不符合中国大部分幼儿园, 因此我们要制造出适合本地、本土的资源, 有利 
于孩子健全人格的发展的玩具。

我们要研究我们的国情、我们的家庭和我们的孩子。我们是一个怎样 的国家, 我们国家的教育问题在哪些方面, 我们孩子需要什么样的教育, 我 们要研究我们国家目前存在的问题, 然后去解决问题, 让老师以及家长能 够给孩子提供一个良好发展的空间。现在很多家长倾向于学习西方的教育 思想和方法, 借鉴外国先进的教育理论是很好的, 但是我们教育的土壤是 中国的国情, 所以我们要结合中国国情和实际情况, 来解决中国的教育问 题, 不能完全照搬外国的教育思想。因此, 寻求中国化和科学化是当前学前 教育研究所要追求的目标之一。

2.3注重幼儿教育研究方法中的选择与突破

陈鹤琴的研究中, 非常重视研究方法的选择与突破, 有的方法在其运 用的过程中还有所创新或突破。例如在考察当时幼稚园的现状时, 选择的 是问卷调查的方式, 结果发现回收率太低, 所得数据资料不能反映其实际 情况, 后面又采用访谈法进行调查。而在信息发达的今天, 问卷调查的回收 不再是问题, 可以利用各种软件通过手机就进行填写, 可是对于填写人的 真实想法却不能够如实反映, 而对于儿童教育研究来讲, 由于研究对象的 年龄限制, 问卷法不能够真实的反映, 因此观察法、访谈法、图画分析法等 都会用到, 研究工作者要做到兼容并蓄。

其次, 当前的一线幼教工作者层次参差不齐, 学历偏低, 幼儿园里缺少 具备研究型人才的教师, 而针对在职幼儿教师研究方法的培训又少, 因此 很多一线教师无法从孩子的行为和作品分析其心理特征。但作为学前教育 的研究工作者, 针对学前教育领域研究方法的单一, 更是要学习和借鉴陈 鹤琴对幼儿教育的研究方法。

2. 4应具备全球化视野和本土化研究的思路

当今在全球网络化、人工智能化、教育国际化的背景下, 需要从事幻 教的工作者们具备全球化的视野, 借鉴国际前沿的学前教育理论和经验, 使我国的学前教育事业获得源源不断的新鲜血液, 但是也要做到本土化的 思考。陈鹤琴对于幼儿园课程里面的每个领域都进行了深入的探究, 比如 语言领域, 他关于儿童掌握词汇量的研究, 今天跟世界上的很多语言研究 专家结论是一样的。现如今中国幼教关注儿童每个领域里的关键经验、主 要的学习内容, 陈鹤琴当年已经做这件事情了, 这件事情对于纠正幼儿园
教育的小学化非常重要。反观当今在中国盛行的 “瑞吉欧教育体系”、“奥 尔夫音乐教学”、“戏剧教育” 等享誉国际的幼教理论, 幼教工作者们都需 向陈鹤琴学习, 结合中国幼儿园的实际情况, 使其理论 “中国化”。

2.5加强学前教育领域研究方法的学习

所谓 “工欲善其事, 必先利其器”。陈鹤琴说过, 若得到研究的方法和 精神, 你就可以自由地去开启知识的宝藏了。近年来, 随着国家对学前教育 的重视, 学前教育思想与实践研究的不断深入, 学者们开始对学前教育研 究方法进行反思。关于幼教的研究, 思辨和定性分析为主, 关于量的研究较 少, 质量相结合的研究更少。所以学校在培养未来的幼儿教师时, 需开设关 于研究方法的课程, 给予学生参与幼儿园教师课题的机会, 让她们将所学 运用在实践中, 但不能生搬硬套, 要考虑幼教的特殊性, 必须立足于我国社 会文化传统及幼儿教育的实际需要, 吸收其精华, 运用科学的研究方法, 在 实践中检验其合理性。

总之, 我国学前教育的改革应当学习陈鹤琴的幼儿教育思想。与国际 幼教接轨的同时, 教育要联系中国国情, 教育要联系儿童的实际, 教育要有 社会的内容, 有自然的内容, 一定要坚持中国化的研究思路, 采用适合的研 究方法, 研究我国幼教中存在的问题, 建立具有中国特色的学前教育理论 体系。

\section{[参考文献]}

[1]虞永平.中国幼教之父——陈鹤琴 [M].南京大学出版社,2019.

[2]严碧芳.陈鹤琴幼儿教育科研观探寻及其启示[D].福建师范大学硕 士学位论文,2007.

[3] 严碧芳.关于陈鹤琴幼儿教育思想研究综述[J].儿童发展研究— 一泉州幼儿师范高等专科学校学报,2016(2):(42).

[4]路雪.陈鹤琴幼儿教育研究方法的分析及启示[J].科教文汇(中旬 刊),2012(12):70-71.

[5]柯小卫.陈鹤琴现代儿童教育学说[M].南京大学出版社,2019.

\section{作者简介：}

邓雯雯(1994--), 女, 伦佬族, 贵州省遵义人, 学前教育学硕士, 毕节 幼儿师范高等专科学校学前教育专业教师,研究方向: 学前儿童心理、 幼儿游戏。 